\title{
Patient considerations in the management of menopausal symptoms: role of conjugated estrogens with bazedoxifene
}

This article was published in the following Dove Press journal:

Therapeutics and Clinical Risk Management

7 April 2016

Number of times this article has been viewed

Risa Kagan, ${ }^{1,2}$ Steven R Goldstein, ${ }^{3}$ James H Pickar, ${ }^{4}$ Barry S Komm ${ }^{5}$

'Department of Obstetrics, Gynecology and Reproductive Sciences, University of California, San Francisco, ${ }^{2}$ East Bay Physicians Medical Group, Berkeley, CA, ${ }^{3}$ Department of Obstetrics and Gynecology, New York University School of Medicine, ${ }^{4}$ Department of Obstetrics and Gynecology, Columbia University Medical Center, New York, NY, ${ }^{5}$ Global Medical Affairs, Pfizer Inc., Collegeville, PA, USA

Video abstract

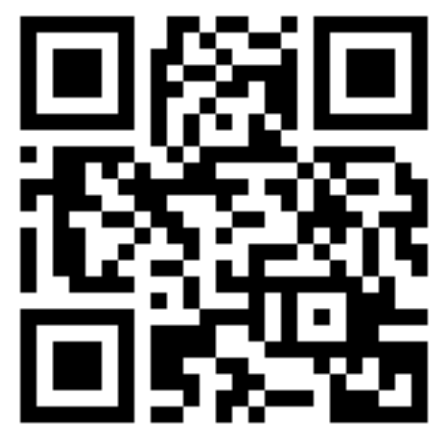

Point your SmartPhone at the code above. If you have a QR code reader the video abstract will appear. Or use: http://youtu.be/wMOwVcNIPnQ

Correspondence: Risa Kagan East Bay Physicians Medical Group, Affiliated with Sutter East Bay Medical Foundation, 2500 Milvia Street, Berkeley, CA 94704, USA

$\mathrm{Tel}+\mathrm{I} 5102045600$

Fax + | 510204546 |

Email kaganr@sutterhealth.org
Abstract: Menopausal symptoms (eg, hot flushes and vaginal symptoms) are common, often bothersome, and can adversely impact women's sexual functioning, relationships, and quality of life. Estrogen-progestin therapy was previously considered the standard care for hormone therapy (HT) for managing these symptoms in nonhysterectomized women, but has a number of safety and tolerability concerns (eg, breast cancer, stroke, pulmonary embolism, breast pain/tenderness, and vaginal bleeding) and its use has declined dramatically in the past decade since the release of the Women's Health Initiative trial results. Conjugated estrogens paired with bazedoxifene (CE/BZA) represent a newer progestin-free alternative to traditional HT for nonhysterectomized women. CE/BZA has demonstrated efficacy in reducing the frequency and severity of vasomotor symptoms and preventing loss of bone mineral density in postmenopausal women. CE/BZA provides an acceptable level of protection against endometrial hyperplasia and does not increase mammographic breast density. Compared with traditional estrogen-progestin therapy, it is associated with lower rates of breast pain/tenderness and vaginal bleeding. Patientreported outcomes indicate that CE/BZA improves menopause-specific quality of life, sleep, some measures of sexual function (especially ease of lubrication), and treatment satisfaction. This review looks at the rationale for selection and combination of CE with BZA at the dose ratio in the approved product and provides a detailed look at the efficacy, safety, tolerability, and patient-reported outcomes from the five Phase III trials. Patient considerations in the choice between CE/BZA and traditional HT (eg, tolerability, individual symptoms, and preferences for route of administration) are also considered.

Keywords: menopause, conjugated estrogens/bazedoxifene, hormone therapy, hot flashes, osteoporosis, safety

\section{Introduction}

Vasomotor symptoms (VMSs) of menopause occur in $\sim 55 \%-90 \%$ of women, ${ }^{1-5}$ and $\sim 70 \%$ of women with these hot flushes and night sweats find them bothersome. ${ }^{6}$ In addition, $\sim 40 \%-70 \%$ of postmenopausal women experience vaginal $/$ sexual symptoms (eg, discomfort, dryness, soreness, itching, burning, or pain on contact, dyspareunia, diminished libido, and avoidance of intimacy) $;^{3,5}$ three-fourths of these women say vaginal symptoms have a negative impact on their lives. ${ }^{3}$ Life expectancy is increasing, ${ }^{7}$ and data suggest, for some women, menopausal symptoms may last many more years than previously suspected. ${ }^{1,4,5,8}$

This review of current and emerging pharmacologic therapies for bothersome menopausal symptoms focuses on efficacy, safety, and patient considerations regarding use of conjugated estrogens/bazedoxifene (CE/BZA). CE/BZA is a relatively new treatment 
for women with a uterus who experience moderate-to-severe VMSs; CE/BZA also helps preserve bone mineral density (BMD). CE/BZA provides a progestin-free alternative to traditional estrogen plus progestin therapy for women with a uterus and seeking treatment for menopausal symptoms. As reviewed in this article, by combining estrogens with a selective estrogen receptor modulator (SERM) instead of a progestin, CE/BZA not only offers endometrial protection but may also avoid breast stimulation and have fewer adverse events typically associated with progestin use (eg, breast pain and vaginal bleeding).

\section{Current and emerging management of menopausal symptoms Oral hormone therapy}

According to numerous international guidelines and expert consensus statements, oral hormone therapy (HT) is safe and effective to start in younger postmenopausal women (ie, those $<60$ years of age or those whose last menstrual period was $\leq 10$ years ago) who have bothersome menopausal symptoms and/or require osteoporosis prevention. ${ }^{9-14}$ The optimal duration of HT use is unknown, but the lowest effective dose should be used for the shortest time needed for symptom control; ${ }^{10,11}$ duration should also be consistent with the patient's treatment goals. Given the long duration of menopausal symptoms, it may be appropriate to extend the duration of HT use beyond 5 years for some women who continue to require symptom relief ${ }^{10,11,13-16}$ and osteoporosis prevention, particularly if they are not candidates for other osteoporosis therapies. ${ }^{9}$ The decision of when to terminate HT use should be based on an individualized assessment of the risks and benefits, and should include patient counseling regarding risks of breast cancer and stroke. ${ }^{15}$

Much of what is known from clinical trials about the riskbenefit profile of HT for the prevention of chronic disease has been derived from the two large $(\mathrm{N}=27,347)$, randomized, double-blind, placebo-controlled Women's Health Initiative (WHI) trials. ${ }^{17-19}$ These trials were conducted in postmenopausal women 50-79 years of age (mean age, 63-64 years) who were not required to have menopausal symptoms. ${ }^{17-19}$ (In fact, at baseline, only $12.7 \%$ of women randomized to conjugated estrogens/ medroxyprogesterone acetate [CE/MPA] and $12.2 \%$ of those in the placebo group had moderate or severe VSMs. ${ }^{20}$ ).

Both the study of CE alone in hysterectomized women and the study of CE/MPA in nonhysterectomized women failed to demonstrate a reduction in coronary heart disease (CHD) in their overall population, which was the primary efficacy end point. ${ }^{17,18}$ The CE/MPA trial was terminated early by its data safety and monitoring board based on the lack of cardioprotection (and possible increase in CHD) coupled with increased risks of breast cancer, stroke, and pulmonary embolism. ${ }^{18}$ The trial of CE alone was subsequently terminated early by the National Institutes of Health based on the lack of cardioprotection and increased risk of stroke, despite the fact that none of the predetermined stopping points had been met. ${ }^{17}$ Although CE/MPA was associated with increased risks of breast cancer and related mortality, ${ }^{21,22}$ no such increases were found in the trial of CE alone; in fact, there was a possible protective effect that became statistically significant in the postintervention period. ${ }^{19,23}$ Thus, CE alone from a relative risk perspective appeared to be safer than CE/MPA with regard to risks of breast cancer and CHD. ${ }^{19}$ Furthermore, progestin-related adverse effects (eg, breast tenderness and vaginal bleeding) are often poorly tolerated and may contribute to poor compliance and discontinuation of HT. ${ }^{24,25}$ However, omitting the progestin and giving $\mathrm{CE}$ alone is not an option for nonhysterectomized women because unopposed estrogens can result in hyperplasia and other unwanted effects on the endometrium in a menopausal woman. ${ }^{13}$ The inclusion of a progestin has been clearly demonstrated to counter these effects. ${ }^{12,13}$

Benefits of HT identified in the WHI trials include significant reductions in osteoporotic fractures, ${ }^{17-19}$ self-reported VMSs, diabetes, joint pain, and (for CE/MPA only) colorectal cancer. ${ }^{19}$ It should be noted that findings from the WHI trials, both positive and negative, apply specifically to $\mathrm{CE}$ and CE/MPA; it is unknown whether similar results would be obtained with other HT formulations.

Rates of HT use have declined dramatically since the WHI trials, such that HT is now used by $<10 \%$ of postmenopausal women in most developed countries in Europe (Figure 1A) and the USA (Figure 1B). ${ }^{26,27}$ Given the high prevalence of bothersome symptoms, ${ }^{1,6}$ low rates of HT use suggest undertreatment of menopausal symptoms. Indeed, a survey of postmenopausal women in the USA, conducted by the Endocrine Society, revealed that nearly three-fourths of women with menopausal symptoms had not been treated for them. ${ }^{28}$ Untreated VMSs are associated with greater absenteeism and health care costs, as well as impaired quality of life and personal relationships. ${ }^{29,30}$ A recent survey of Australian women determined that moderate-to-severe VMSs have an adverse impact on psychological well-being that is comparable to that of housing insecurity and greater than that of obesity or being a caregiver for a family member with special needs. ${ }^{31}$ Vaginal discomfort related to menopause can interfere with libido, intimate relationships, self-esteem, and quality of life. ${ }^{3,32,33}$

The decline in use of traditional HT has been accompanied by increasing popularity of custom-compounded 

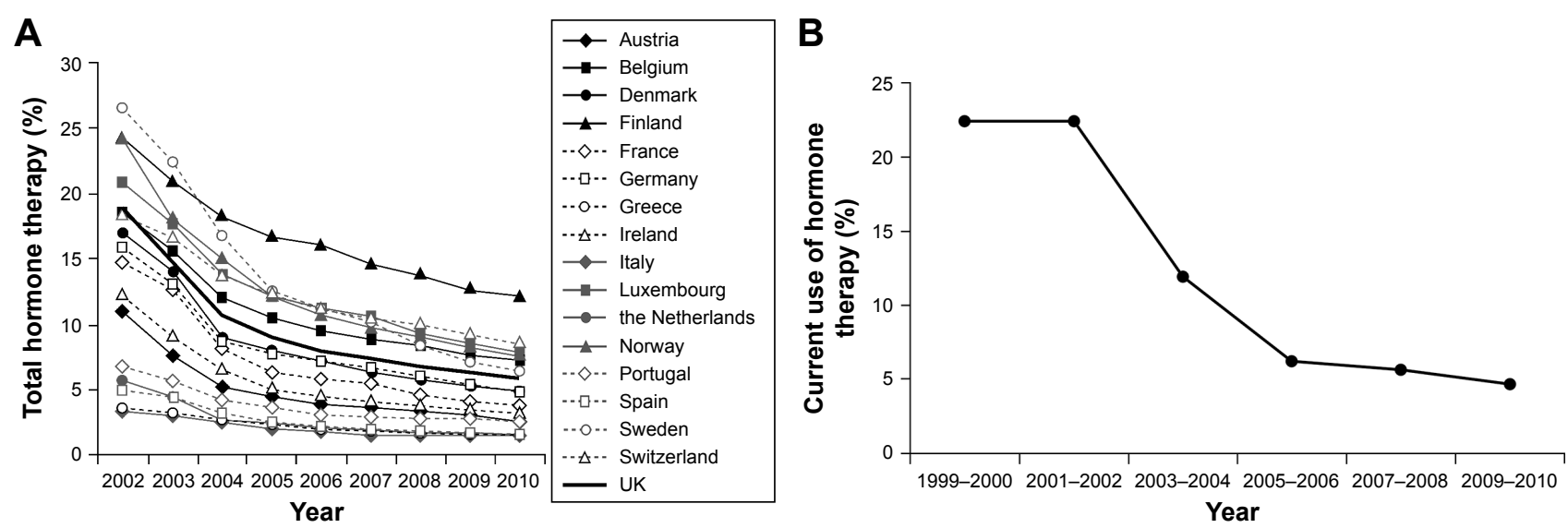

Figure I Changes in estimated proportion of women aged 45-69 years using menopausal hormone therapy in 17 European countries from 2002 to 2010 (A). Changes in estimated proportion of women aged $\geq 40$ years reporting current use of oral postmenopausal hormones from 1999 to 2010 in the USA (B).

Notes: (A) Reprinted from Maturitas, 2014;79(3), Ameye L, Antoine C, Paesmans M, de Azambuja E, Rozenberg S, Menopausal hormone therapy use in 17 European countries during the last decade, Pages $287-291,{ }^{26}$ Copyright $@ 2014$, with permission from Elsevier. (B) Data from Sprague et al. ${ }^{27}$

bioidentical HT, which is used by an estimated $1-2.5$ million US women annually. ${ }^{34}$ This trend is troublesome given the lack of evidence supporting the efficacy and safety of compounded bioidentical HT and the potential for additional risks due to variable purity, potency, and quality ${ }^{35}$

Benefits and safety of HT for treatment of menopausal symptoms in younger women shortly after menopause were not addressed by the WHI results. Reanalyses of the WHI trials suggested lower risks of CHD, stroke, and a global index of events (ie, CHD, stroke, pulmonary embolism, breast cancer, colorectal cancer, endometrial cancer, hip fracture, or all-cause mortality) among women in their $50 \mathrm{~s}$ and/or women closer to menopause compared with older women and women who have been postmenopausal longer. ${ }^{36}$ For example, in the trial of $\mathrm{CE}$ alone, although not statistically significant, the hazard ratio (95\% confidence interval [CI]) for CHD was 0.63 (0.36-1.09) in women 50-59 years indicating a possible protective effect, whereas it was $0.94(0.71-1.24)$ in women aged 60-69 years and $1.13(0.82-1.54)$ in women 70-79 years of age. ${ }^{36}$ Breast cancer risk with CE/MPA, however, was not lower in this younger group. ${ }^{22}$

\section{Other forms of hormonal therapy}

HT formulations with vaginal or transdermal routes of administration are also available. Selection of the route of administration should take into account the individual woman's symptoms and preferences. Vaginal estrogens are recommended if the only bothersome menopausal symptoms are genitourinary in nature. ${ }^{11,13,37}$ This is likely to be a small proportion of younger postmenopausal women because a majority of such women have VMSs. ${ }^{2}$

It has been hypothesized based on observational data that transdermal estrogens' avoidance of first-pass hepatic metabolism may result in reduced risk of venous thromboembolism (VTE), and that lower doses used with transdermal administration may also result in lower rates of dose-related adverse effects (eg, breast tenderness and vaginal bleeding).$^{38}$ However, most of these safety and tolerability outcomes have not been compared in head-to-head randomized trials of transdermal versus oral HT, so these claims are as yet unproven.

In fact, in a subset analysis of the Kronos Early Estrogen Prevention Study (KEEPS), one of the few comparative trials, the authors concluded that there was no significant difference between transdermal 17- $\beta$-estradiol $50 \mu \mathrm{g} / \mathrm{d}$ with oral micronized progesterone $200 \mathrm{mg} / \mathrm{d}$, oral CE $0.45 \mathrm{mg} / \mathrm{d}$ with oral micronized progesterone $200 \mathrm{mg} / \mathrm{d}$, or placebo with regard to the occurrence or the severity of breast pain. ${ }^{39}$ Although the incidence of breast pain (collected at baseline and yearly with the Mayo Clinic Breast Pain Questionnaire) before and during treatment was not significantly different across the treatment groups ( $P=0.78$ before treatment; $P=0.18$ during treatment), a numerically higher proportion of women developed new-onset breast pain during treatment in the transdermal group (18 out of 31 women without baseline pain [58\%]) than in the oral HT group (12 out of 32 women without baseline pain [38\%]) or the placebo group (15 out of 39 women without baseline pain [38\%]) (Figure 2).$^{39}$ The transdermal and oral formulations both had neutral effects on endothelial dysfunction (measured via pulse volume digital tonometry) and, compared with placebo, both significantly improved VMSs to a similar extent. ${ }^{40}$

The KEEPS study was not designed to evaluate differences between the treatments with regard to VTE rates. However, KEEPS did evaluate effects on platelet count and function (as a marker of thrombotic risk) in a subgroup of 117 women and found that neither formulation had a significant effect on general platelet characteristics, including platelet 


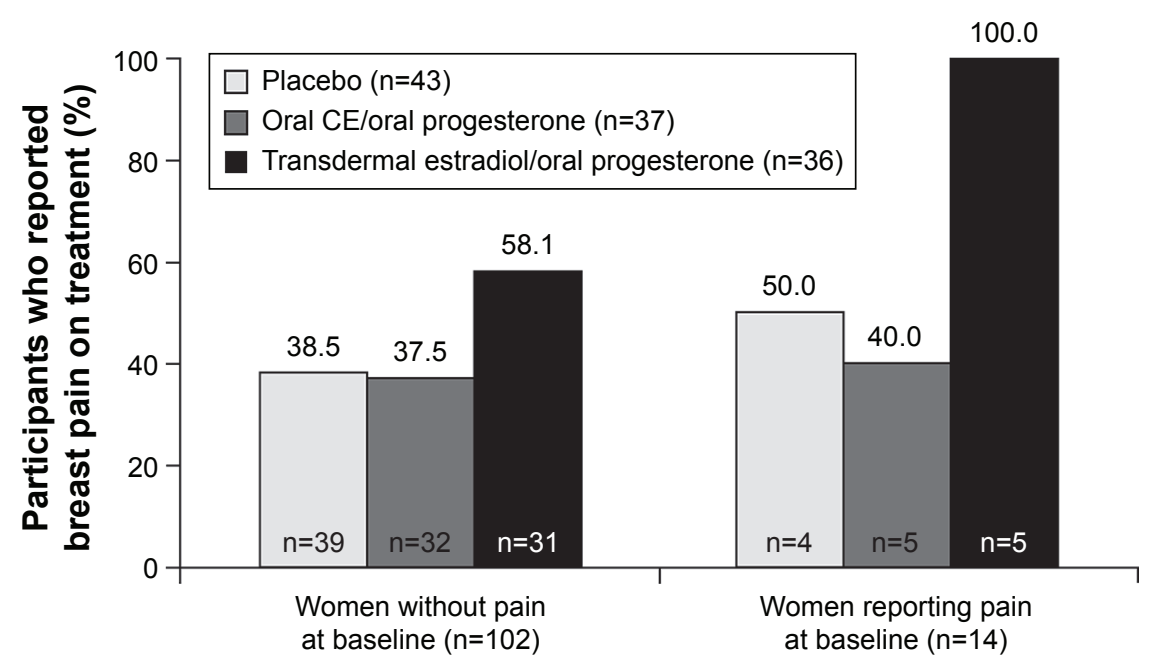

Figure 2 Incidence of breast pain during treatment with transdermal estradiol/oral micronized progesterone, oral CE/oral micronized progesterone, or placebo in women with and without baseline pain in KEEPS.

Note: $P=0.18$ for Pearson's chi-square test of differences among treatment groups versus baseline.

Abbreviations: CE, conjugated estrogens; KEEPS, Kronos Early Estrogen Prevention Study.

count, spontaneous micro-aggregation (a test of platelet sensitivity), or expression of surface receptors for P-selectin or fibrinogen. ${ }^{41}$ Both oral and transdermal estrogens had comparable effects on platelet proteins, and transdermal estrogens (but not oral estrogens) increased the number of tissue factor-positive microvesicles and platelet-derived microvesicles, indicative of cellular activation and a procoagulant environment. ${ }^{41}$

Ospemifene, a SERM, is an oral therapy indicated for dyspareunia. ${ }^{42}$ In two 12 -week Phase III clinical trials, ospemifene at the approved dose of $60 \mathrm{mg} / \mathrm{d}$ significantly improved the vaginal maturation index $(P<0.001)$ and vaginal $\mathrm{pH}(P<0.001)$ and reduced dyspareunia $(P<0.05)$ compared with placebo in postmenopausal women with vulvar-vaginal atrophy, ${ }^{43,44}$ which is now considered a component of the genitourinary syndrome of menopause. ${ }^{45}$ Hot flushes were an adverse event, ${ }^{43,44,46}$ typical of SERMs, ${ }^{47-49}$ so ospemifene may not be an ideal choice for women who are already experiencing bothersome VMSs. Endometrial effects of ospemifene were reported to be negligible ${ }^{43}$ or not clinically meaningful, ${ }^{44}$ although minor increases in endometrial thickness were observed, along with a couple of cases of active endometrial proliferation. There were no cases of endometrial hyperplasia or carcinoma observed in the core studies or a 40-week extension of the first trial. ${ }^{43,46}$

Finally, as noted earlier, CE/BZA is the first successfully developed progestin-free, estrogen-based therapy for nonhysterectomized women consisting of a combination of estrogens and a SERM. CE/BZA is reviewed in detail beginning on the next page.

\section{Nonhormonal therapies}

The selective serotonin reuptake inhibitor paroxetine is the first nonhormonal prescription therapy approved by the US Food and Drug Administration for treatment of moderateto-severe menopausal VMSs. ${ }^{50}$ In two randomized Phase III clinical trials, paroxetine reduced moderate-to-severe VMSs by $\sim 0.9 / \mathrm{d}$ and $1.4 / \mathrm{d}$ relative to placebo at week 12 $\left(P<0.01\right.$ and $P=0.0001$, respectively).$^{51}$ As the average daily number of hot flushes at baseline was 11.8 and 10.8, this amounts to a $7.6 \%$ and $13.0 \%$ reduction in hot flush frequency for paroxetine relative to placebo. VMS severity was also significantly reduced at week 12 in one study $(P<0.05){ }^{51}$ Paroxetine did not adversely affect weight or sexual function. ${ }^{52}$ No comparative data are available, but the magnitude of effect paroxetine has on VMSs appears to be less than what is typically seen with HT. Paroxetine has no favorable bone effects (unlike estrogens), and despite the low dose $(7.5 \mathrm{mg} / \mathrm{d})$ used for this indication, it may have adverse effects characteristic of selective serotonin reuptake inhibitors (eg, fatigue and somnolence). ${ }^{50}$ Thus, paroxetine should be considered an alternative for women who are not candidates for HT.

The serotonin-norepinephrine reuptake inhibitor desvenlafaxine is approved for treatment of menopausal symptoms in Mexico, the Philippines, and Thailand, but not the USA or most of Europe. In a randomized controlled trial, desvenlafaxine $100 \mathrm{mg} / \mathrm{d}$ reduced the frequency of moderate-to-severe hot flushes by $2-3 / \mathrm{d}$ relative to placebo $(P<0.001)$, and also significantly reduced hot flush severity $(P<0.01)$; these effects were well maintained for 12 months. ${ }^{53}$ 


\section{Emerging treatments}

A number of investigational therapies are in late-stage clinical trials. TX-004HR is a vaginal estradiol suppository that is currently in Phase III development. ${ }^{54}$ TX-001HR is an oral HT that combines $17-\beta$-estradiol and progesterone into a single peanut-oil-free capsule, whereas these hormones are currently available only separately or through pharmacy compounding. ${ }^{55,56}$ Pharmacokinetic results show that the bioavailability of estradiol and progesterone with the new combination product is similar to that of commercially available formulations of the separate components. ${ }^{56} \mathrm{~A}$ Phase III trial of TX-001HR is ongoing. ${ }^{55,57}$

Nonhormonal psychotropic therapies (eg, escitalopram, ${ }^{58}$ sertraline, ${ }^{59}$ venlafaxine,${ }^{60}$ and gastroretentive gabapentin ${ }^{61}$ ) have shown modest reductions in hot flushes in clinical studies of postmenopausal women. However, with the exception of gastroretentive gabapentin, they generally have not been studied in large populations of women with at least seven moderate-to-severe hot flushes per day, or 50/wk, as required by the Food and Drug Administration.

\section{Rationale for development of CE/BZA}

In an attempt to develop a safe, well-tolerated, progestin-free option for nonhysterectomized women, it was hypothesized that combining estrogens with a SERM might retain beneficial estrogenic effects on VMSs and bone while blocking the known estrogenic effects of estrogens on the endometrium and breast tissue. ${ }^{62,63}$

The combination CE/BZA has proven uniquely suitable for development. $\mathrm{CE}$ has a long history of use and has been well studied. At a dose of $0.625 \mathrm{mg} / \mathrm{d}, \mathrm{CE}$ was extensively investigated in the WHI trials because it was the most commonly used estrogen formulation. ${ }^{19}$ Although estradiol is sometimes touted as a more natural or bioidentical hormone, it is unclear whether there is an actual advantage to one estrogen formulation over another. Observational studies largely report little to no statistically significant difference in their relative effects on VTE, CHD, and stroke risk, ${ }^{64-66}$ and no randomized comparative trials with adequate power to evaluate these endpoints have been conducted. The KEEPS study, described earlier, is the only direct comparison of their relative safety.

BZA is a unique SERM in that it degrades the estrogen receptors in breast and endometrial tissue, similar to fulvestrant. ${ }^{67-72}$ Preclinical investigations showed that BZA countered the stimulating effects of estrogens in the endometrium and breast when they were coadministered, whereas other SERMs provided less protection against stimulation of these tissues. ${ }^{67,68,70,71,73,74}$ In fact, a clinical trial of $17-\beta$ estradiol/raloxifene found this combination to result in significant increases in endometrial thickness; in addition, among 91 women who underwent postbaseline endometrial biopsy, cases of endometrial proliferation (estradiol/raloxifene: $n=7$; raloxifene alone: $\mathrm{n}=3$ ) and hyperplasia (estradiol/raloxifene: $\mathrm{n}=2$; raloxifene alone: $\mathrm{n}=0$ ) were found. ${ }^{75}$

After selection of CE and BZA as the best combination for development, it was necessary to identify the optimal dose ratio that would allow for both endometrial protection and therapeutic efficacy. Based on results of Phase II and III dose-finding studies, ${ }^{76-78}$ combinations of BZA $20 \mathrm{mg}$ with either CE $0.45 \mathrm{mg}$ or $0.625 \mathrm{mg}$ were determined to best achieve this balance. A series of Phase III trials named the Selective estrogens, Menopause, And Response to Therapy (SMART) trials provide data on the efficacy and safety of these two doses of CE/BZA.

\section{Efficacy of CE/BZA in the SMART trials}

The first two SMART trials, SMART-1 and SMART-2, demonstrated significant reductions in hot flush frequency and severity in generally healthy postmenopausal women who had at least seven moderate or severe hot flushes per day or 50/wk at baseline. ${ }^{78,79} \mathrm{In}$ these two trials, CE $0.45 \mathrm{mg} /$ BZA $20 \mathrm{mg}$ and CE $0.625 \mathrm{mg} / \mathrm{BZA} 20 \mathrm{mg}$ reduced the mean number of moderate-to-severe hot flushes by $\sim 8-9 / \mathrm{d}$ at 12 weeks of treatment compared with being reduced by $\sim 2.5$ and 5 in the placebo groups of SMART-1 and SMART-2, respectively (all $P<0.001$ vs placebo); improvements were sustained throughout 2 years of treatment in SMART-1. ${ }^{78,79}$ (It should be noted that placebo response rates are typically high [eg, 52\% at week 12 in SMART-2 ${ }^{79}$ ] and may be sustained in treatment of menopausal hot flushes. ${ }^{80}$ Similarly, in SMART-1 and SMART-2, respectively, the mean daily hot flush severity rating $(1=$ mild, $2=$ moderate, and $3=$ severe) decreased by 1.0 and 0.9 in the CE $0.45 \mathrm{mg} / \mathrm{BZA}$ $20 \mathrm{mg}$ arms and 1.1 and 1.2 points in the CE $0.625 \mathrm{mg} / \mathrm{BZA}$ $20 \mathrm{mg}$ arms compared with reductions of 0.21 and 0.26 in the placebo arms (all $P<0.001$ vs placebo) (data on file). ${ }^{78,79} \mathrm{~A}$ post hoc analysis of these two trials confirmed that women with both $<5$ and $\geq 5$ years since menopause achieved significant reductions in hot flush frequency and severity. ${ }^{81}$

CE/BZA (CE $0.45 \mathrm{mg} / \mathrm{BZA} 20 \mathrm{mg}$; Duavee ${ }^{\circledR}$ ) is approved for the prevention of postmenopausal osteoporosis in the USA and Korea. CE/BZA was shown to reduce bone loss in SMART-1, SMART-4, and SMART-5, whereas patients in 
the placebo groups lost BMD; CE $0.45 \mathrm{mg} / \mathrm{BZA} 20 \mathrm{mg}$ and CE $0.625 \mathrm{mg} / \mathrm{BZA} 20 \mathrm{mg}$ were associated with gains in nearly all BMD outcomes, albeit more modest ones compared with CE/MPA (Table 1). ${ }^{82-84} \mathrm{CE} / \mathrm{BZA}$ also significantly reduced bone turnover compared with placebo based on changes in serum levels of osteocalcin and C-telopeptide. ${ }^{82-84}$

$\mathrm{CE} / \mathrm{BZA}$ has not been approved for treatment of vulvarvaginal symptoms of menopause. However, women taking $\mathrm{CE} / \mathrm{BZA}$ for other indications may experience some benefits with regard to vaginal health. The SMART-3 trial enrolled postmenopausal women with $<5 \%$ superficial cells on vaginal cytological smear; a vaginal $\mathrm{pH}>5$; and vaginal dryness, itching/irritation, or pain with sexual intercourse were their most bothersome symptom. ${ }^{85}$ At 12 weeks, both doses significantly increased superficial cells, decreased parabasal cells, alleviated vaginal dryness, and improved self-reported sexual function, especially ease of lubrication. ${ }^{85,86}$ The higher dose (which is not commercially available) also significantly decreased vaginal $\mathrm{pH}$ and improved the most bothersome vaginal symptom. ${ }^{85}$

\section{Safety of CE/BZA in the SMART trials Endometrial safety}

CE/BZA's effect on the risk of endometrial hyperplasia at 12 months was evaluated as a primary end point of SMART-1 and SMART-5. ${ }^{77,84}$ Without a progestin, CE $0.45 \mathrm{mg} / \mathrm{BZA}$ $20 \mathrm{mg}$ and CE $0.625 \mathrm{mg} / \mathrm{BZA} 20 \mathrm{mg}$ were associated with a $<1 \%$ incidence of hyperplasia with an upper limit of the $95 \%$ CI $<2 \%$, which was similar to placebo. ${ }^{77,84}$ This low rate of endometrial hyperplasia meets the US and European Union regulatory requirements for endometrial safety. ${ }^{87,88} \mathrm{Of}$ note, CE/BZA formulations containing only $10 \mathrm{mg}$ of BZA in SMART-1 and a formulation of CE $0.625 \mathrm{mg} / \mathrm{BZA} 20 \mathrm{mg}$ used only in SMART-4 that was found to have reduced BZA bioavailability were associated with potentially inadequate endometrial protection, which attests to the importance of utilizing the currently approved combination of CE/BZA to ensure that the optimal dose ratio is maintained. ${ }^{77,83} \mathrm{BZA}$ is believed to block estrogen-stimulated proliferation in the endometrium by inhibiting estrogen-mediated expression of proliferative genes while maintaining expression of antiproliferative genes, ${ }^{89}$ this

Table I Effects of CE/BZA on BMD at month 12 in SMART-I, \& SMART-4," and SMART-5\$ (data on file)

\begin{tabular}{|c|c|c|c|c|}
\hline & \multicolumn{4}{|c|}{ BMD, adjusted mean (SE) percentage change from baseline at month I 2} \\
\hline & $\begin{array}{l}\text { CE } 0.45 \mathrm{mg} / \\
\text { BZA } 20 \mathrm{mg}\end{array}$ & $\begin{array}{l}\text { CE } 0.625 \mathrm{mg} / \\
\text { BZA } 20 \mathrm{mg}\end{array}$ & $\begin{array}{l}\text { CE } 0.45 \mathrm{mg} / \\
\text { MPA } 1.5 \mathrm{mg}\end{array}$ & Placebo \\
\hline \multicolumn{5}{|c|}{ SMART-I substudy Ia } \\
\hline Lumbar spine & $1.45(0.25)^{*}$ & $1.59(0.25)^{*}$ & - & $-1.14(0.25)$ \\
\hline Total hip & $1.06(0.17)^{*}$ & $1.10(0.17)^{*}$ & - & $-0.44(0.17)$ \\
\hline Femoral neck & $0.65(0.2 \mathrm{I})^{*}$ & $0.58(0.2 \mathrm{I})^{*}$ & - & $-0.67(0.21)$ \\
\hline Femoral trochanter & $1.86(0.28)^{*}$ & $1.72(0.28) *$ & - & $-0.09(0.28)$ \\
\hline \multicolumn{5}{|c|}{ SMART-I substudy II } \\
\hline Lumbar spine & $1.08(0.28)^{*}$ & $1.05(0.29)^{*}$ & - & $-1.78(0.29)$ \\
\hline Total hip & $0.64(0.20)^{*}$ & $0.26(0.21)^{*}$ & - & $-0.86(0.21)$ \\
\hline Femoral neck & $-0.16(0.29)^{* *}$ & $0.12(0.30)^{*}$ & - & $-1.27(0.29)$ \\
\hline Femoral trochanter & $0.79(0.27)^{*}$ & $0.85(0.28)^{*}$ & - & $-1.07(0.28)$ \\
\hline \multicolumn{5}{|l|}{ SMART-4 } \\
\hline Lumbar spine & $0.80(0.24)^{*}$ & $0.80(0.24)^{*}$ & $2.22(0.37)^{*}$ & $-1.56(0.35)$ \\
\hline Total hip & $0.62(0.19)^{*}$ & $0.84(0.19)^{*}$ & $\mathrm{I} .47(0.29)^{*}$ & $-0.99(0.27)$ \\
\hline Femoral neck & $0.53(0.24)^{*}$ & $0.69(0.24)^{*}$ & $0.20(0.36)^{*}$ & $-1.95(0.34)$ \\
\hline Femoral trochanter & $1.20(0.24)^{*}$ & $1.18(0.24)^{*}$ & $2.29(0.36)^{*}$ & $-1.05(0.34)$ \\
\hline \multicolumn{5}{|l|}{ SMART-5 } \\
\hline Lumbar spine & $0.24(0.29)^{*}$ & $0.60(0.27)^{*}$ & $1.30(0.39)^{*}$ & $-1.28(0.28)$ \\
\hline Total hip & $0.50(0.20)^{*}$ & $0.89(0.18)^{*}$ & $0.71(0.26)^{*}$ & $-0.72(0.18)$ \\
\hline Femoral neck & $-0.07(0.26)^{* *}$ & $0.84(0.24)^{*}$ & $0.52(0.34)^{*}$ & $-1.00(0.24)$ \\
\hline Femoral trochanter & $\mathrm{I} .3 \mathrm{I}(0.3 \mathrm{I})^{*}$ & I.57 (0.29)* & $\mathrm{I} .35(0.4 \mathrm{I}) *$ & $-0.29(0.29)$ \\
\hline
\end{tabular}

Notes: aSMART-I substudy I: women $>5$ years postmenopausal; SMART-I substudy II: women I-5 years postmenopausal. Both substudies enrolled women with lumbar spine or total hip BMD T-scores between $-\mathrm{I}$ and -2.5 (inclusive) and at least one additional osteoporosis risk factor at screening. Risk factors included Caucasian or Asian race, early menopause ( $\leq 40$ years of age), family history of osteoporosis, current smoking, low-calcium diet, history of excessive alcohol use, inactive lifestyle, and a thin and/or small frame (weight $<50 \mathrm{~kg}$ and/or BMI $<18 \mathrm{~kg} / \mathrm{m}^{2}$ ). ${ }^{*} \mathrm{P}<0.00$ I versus placebo. ${ }^{* * P}<0.01$ versus placebo. ${ }^{*}$ Reprinted from Fertil Steril, 2009;92(3), Lindsay R, Gallagher JC, Kagan R, Pickar JH, Constantine G, Efficacy of tissue-selective estrogen complex of bazedoxifene/conjugated estrogens for osteoporosis prevention in at-risk postmenopausal women, pages 1045-1052, ${ }^{82}$ Copyright @2009, with permission of Elsevier. "Effects of bazedoxifene/conjugated estrogens on endometrial safety and bone in postmenopausal women, Mirkin S, Komm BS, Pan K, Chines AA, Climacteric, 2013;16(3):338-346, ${ }^{83}$ reprinted by permission of the publisher (Taylor and Francis Ltd, http://www.tandfonline.com). \$Adapted with permission of Endocrine Society, from Effects of bazedoxifene/conjugated estrogens on the endometrium and bone: a randomized trial, Pinkerton JV, Harvey JA, Lindsay R, et al; SMART-5 Investigators, J Clin Endocrinol Metab, 2014;99(2):El89-EI98, ${ }^{84}$ Copyright (C I952; permission conveyed through Copyright Clearance Center, Inc. Abbreviations: CE, conjugated estrogens; BZA, bazedoxifene; BMD, bone mineral density; SMART, Selective estrogens, Menopause, And Response to Therapy; SE, standard error; MPA, medroxyprogesterone acetate; BMI, body mass index. 
differs from progestins, which counter estrogenic activity in the endometrium by inducing epithelial differentiation as well as downregulation of estrogen receptors. ${ }^{90}$

In a pooled analysis of gynecologic safety data from all five SMART trials, ${ }^{91}$ there was only one case of endometrial cancer, which occurred in a woman taking CE $0.45 \mathrm{mg} / \mathrm{BZA}$ $20 \mathrm{mg}$. The incidence rate for endometrial cancer among women taking CE $0.45 \mathrm{mg} / \mathrm{BZA} 20 \mathrm{mg}$ was determined to be 0.4 per 1,000 woman-years ( $95 \%$ CI, $0.0-2.4)$ with a relative risk compared with placebo of 0.9 (95\% CI, 0.2-4.8). (A relative risk of 1 would indicate equivalent risk between the two treatments, whereas a relative risk $<1$ suggests a protective effect and a relative risk $>1$ suggests an association with increased risk).

\section{Breast safety}

Effects of any menopausal hormonal therapy on breast safety must be carefully evaluated. CE and BZA each separately have demonstrated good breast safety in clinical trials. In the WHI trial, CE alone in hysterectomized women did not adversely affect the breast; in fact, it was associated with a reduction in breast cancer incidence and related mortality that persisted even after discontinuation. ${ }^{23}$ In a 7-year clinical trial of postmenopausal women with osteoporosis, BZA alone had a neutral effect on the breast, with a low breast cancer incidence and breast stimulation similar to that of placebo. ${ }^{92}$

CE/BZA did not significantly affect the percentage of dense breast tissue on mammography compared with placebo in substudies of SMART-1 and SMART-5. ${ }^{93,94}$ In contrast, CE/MPA (an active comparator in SMART-5) did significantly $(P<0.001)$ increase breast density compared with placebo, ${ }^{94}$ as it also did in the WHI trial. ${ }^{95}$ These findings are potentially clinically relevant because higher breast density is associated with reduced ability to detect breast cancer on mammography and may be an independent risk factor for breast cancer. ${ }^{96-98}$

In a pooled analysis of all five SMART trials, ${ }^{91}$ the incidence of breast cancer was $0.3 \%$ with CE $0.45 \mathrm{mg} / \mathrm{BZA}$ $20 \mathrm{mg}, 0.0 \%$ with CE $0.625 \mathrm{mg} / \mathrm{BZA} 20 \mathrm{mg}$, and $0.2 \%$ with placebo. The incidence rate per 1,000 woman-years was estimated to be 1.0 (95\% CI, 0.0-3.2), 0.0 (95\% CI, 0.0-1.5), and 1.4 (95\% CI, 0.0-4.2), respectively. Relative risk of breast cancer with CE $0.45 \mathrm{mg} / \mathrm{BZA} 20 \mathrm{mg}$ compared with placebo was 1.1 (95\% CI, 0.3-3.8). The longest SMART trials were 2 years, so longer term safety, including breast cancer risk, remains to be confirmed. $\mathrm{CE}$ alone was given to hysterectomized women in the WHI trial for a median of $\sim 6$ years, and in another study BZA alone was given to women with postmenopausal osteoporosis for up to 7 years, both without evidence of an increase in breast cancer incidence. ${ }^{23,99} \mathrm{CE} /$ BZA has not been studied in women at high risk for breast cancer.

\section{Thromboembolic, cerebrovascular, and cardiovascular safety}

An increased risk of VTE has been reported in users of estrogens as well as users of clinically available SERMS, and this association has been independently found with CE and BZA. In the WHI trial, CE alone was associated with an increased risk of deep vein thrombosis (hazard ratio [HR] 1.48, 95\% CI, 1.06-2.07) and pulmonary embolism, although the latter did not achieve statistical significance (HR 1.35, 95\% CI, 0.89-2.05). ${ }^{19}$ In postmenopausal women with osteoporosis, BZA $20 \mathrm{mg}$ was associated with a statistically significant increase in the risk of deep vein thrombosis over 7 years (HR 3.38, 95\% CI, 1.01-11.39); pulmonary embolism occurred in $2 \%$ of both the BZA and placebo groups. ${ }^{92}$

When CE and BZA are combined, the risk does not appear to be additive. ${ }^{100}$ In a pooled analysis of the five SMART trials, the incidence of VTE was $0.2 \%$ in the CE $0.45 \mathrm{mg} / \mathrm{BZA}$ $20 \mathrm{mg}$ group, $0.0 \%$ in the CE $0.625 \mathrm{mg} / \mathrm{BZA} 20 \mathrm{mg}$ group, and $0.1 \%$ in the placebo group, and all of the VTEs were deep vein thromboses. ${ }^{100}$ In the CE $0.45 \mathrm{mg} / \mathrm{BZA} 20 \mathrm{mg}$ group, the rate per 1,000 woman-years was 0.3 (95\% CI, 0.0-2.0) and the relative risk versus placebo was $0.9(0.2-4.1) .{ }^{100}$ Given the low number of VTE events in the SMART trials and the incomplete understanding as to the mechanism by which estrogens and SERMs may contribute to VTE risk, the true risk of VTE with CE/BZA remains unknown. Because the increased risk of VTE associated with CE has been shown to occur early, particularly in the first 2 years of treatment, with modest increases thereafter, ${ }^{101}$ the low rate of VTE in the 2-year SMART-1 trial (relative risk of VTE for CE/BZA vs placebo: 0.48 [95\% CI, 0.05-4.66]) is reassuring. ${ }^{78}$

Stroke occurred in one SMART trial participant treated with CE $0.45 \mathrm{mg} / \mathrm{BZA} 20 \mathrm{mg}(0.06 \%)$ and one treated with CE $0.625 \mathrm{mg} / \mathrm{BZA} 20 \mathrm{mg}(0.06 \%)$ compared with none in the placebo group. ${ }^{100}$ The rate per 1,000 woman-years was 0.4 (95\% CI, 0.0-2.4) and 0.2 (95\% CI, 0.0-1.9) for the approved dose and higher dose of CE/BZA, respectively, and for both doses, the relative risk versus placebo was 0.9 (95\% CI, 0.2-4.8). ${ }^{100}$ As with VTE, the low number of events prohibits definitive conclusions regarding the effect of $\mathrm{CE} /$ BZA on stroke risk.

In the pooled analysis of the SMART trials, the rate of any $\mathrm{CHD}$ event was $0.3 \%$ with either dose of CE/BZA compared 
with $0.2 \%$ in the placebo group, and the rate of myocardial infarction was $0.2 \%$ for both CE $0.45 \mathrm{mg} / \mathrm{BZA} 20 \mathrm{mg}$ and placebo and $0.1 \%$ with CE $0.625 \mathrm{mg} / \mathrm{BZA} 20 \mathrm{mg}{ }^{100}$ The rate of any CHD event per 1,000 woman-years was 2.6 (95\% CI, 0.0-5.6) with CE 0.45 mg/BZA 20 mg, 1.4 (95\% CI, 0.0-3.9) with CE $0.625 \mathrm{mg} / \mathrm{BZA} 20 \mathrm{mg}$, and 2.0 (95\% CI, 0.0-5.2) with placebo. ${ }^{100}$ The relative risk versus placebo was 0.9 (95\% CI, 0.3-2.9) for the approved dose and 1.0 (95\% CI, 0.3-3.1) for the higher dose. ${ }^{100}$ A pooled analysis of 12- and 24-month data from the three longest trials (SMART-1, SMART-4, and SMART-5) reported that CE/BZA significantly $(P<0.001)$ decreased total cholesterol and low-density lipoprotein cholesterol, and increased highdensity lipoprotein cholesterol and triglycerides compared with placebo - a pattern that is consistent with the effects of traditional HT. ${ }^{102}$

\section{Patient considerations: tolerability of CE/BZA versus other $\mathrm{HT}$}

Breast pain/tenderness and vaginal bleeding are common complaints of women using traditional HT. Based on data from the WHI, users of HT are more than four times as likely to experience breast tenderness or vaginal bleeding compared with nonusers. ${ }^{24}$ In contrast, in SMART-1 and SMART-5, the incidence of breast pain/tenderness with $\mathrm{CE} / \mathrm{BZA}$ was comparable to placebo, whereas significantly $(P<0.001)$ higher rates of breast tenderness were observed with CE/MPA than CE/BZA in SMART-5 (Figure 3). ${ }^{78,84,94}$ Similarly, in SMART-1 and SMART-5, ${ }^{84,103} \mathrm{CE} / \mathrm{BZA}$ was associated with high rates of amenorrhea and low rates of bleeding/spotting, similar to placebo, whereas bleeding/spotting rates were significantly $(P<0.001)$ higher with $\mathrm{CE} / \mathrm{MPA}$ than $\mathrm{CE} / \mathrm{BZA}$ in SMART-5 (Figure 4). ${ }^{104}$ These adverse events may be more than just nuisance effects. Breast pain/tenderness has been reported to be associated with an increase in breast density on mammography ${ }^{95}$ as well as increased risk of breast cancer. ${ }^{105}$ Breakthrough bleeding is not only inconvenient but can also lead to endometrial sonograms, biopsies, and hysteroscopies, which result in unnecessary anxiety and costs.

In some studies, progestin-based therapies have also been associated with mood symptoms (eg, depression and anxiety). In a randomized, placebo-controlled trial, CE/ MPA was associated with a significant $(P=0.01)$ increase in depression in women who had not undergone hysterectomy, based on daily ratings on the Prospective Record of the Impact and Severity of Menstrual Symptoms calendar (though depressive symptoms were mostly considered mild and not troublesome); no such increase was found among

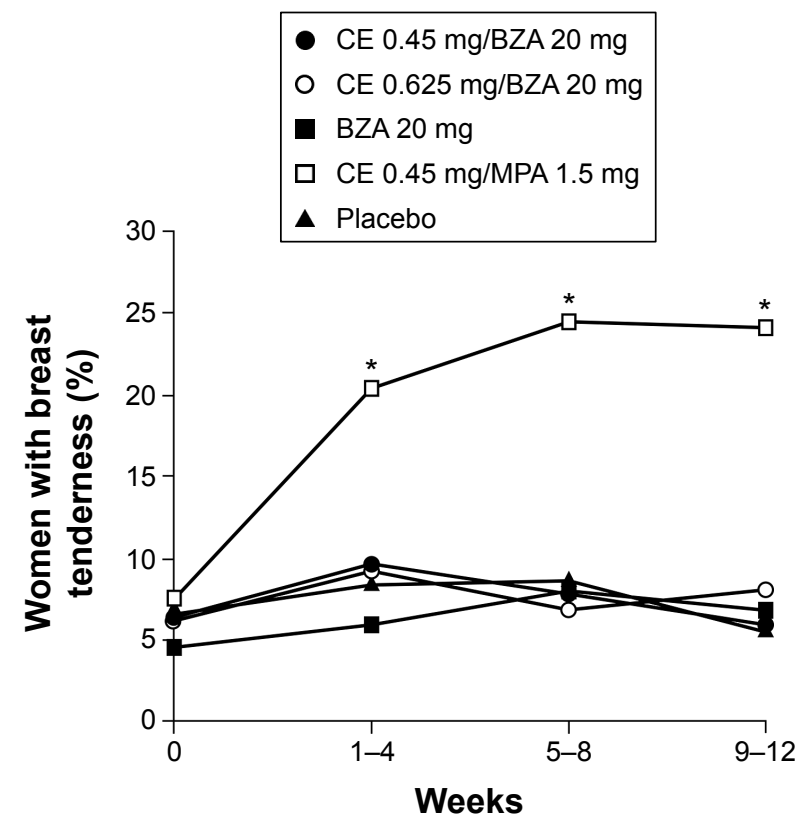

Figure 3 Percentage of women reporting $\geq 1$ day of breast tenderness in daily diaries during 4-week intervals through 12 weeks in SMART-5.

Notes: $* P<0.001$ for CE/MPA versus all other treatment groups. There were no statistically significant differences between either dose of CE/BZA and placebo. Pinkerton JV, Harvey JA, Pan K, et al. Breast effects of bazedoxifene-conjugated estrogens: a randomized controlled trial. Obstet Gynecol. 2013;121(5):959-968.94 Promotional and commercial use of the material in print, digital or mobile device format is prohibited without the permission from the publisher Wolters Kluwer Health. Please contact healthpermissions@wolterskluwer.com for further information.

Abbreviations: SMART, Selective estrogens, Menopause, And Response to Therapy; CE, conjugated estrogens; MPA, medroxyprogesterone acetate; BZA, bazedoxifene.

hysterectomized women taking $\mathrm{CE}$ alone. ${ }^{106}$ A study using data from the Korean National Health and Nutrition Examination Survey V found an increased risk of depression among women who initiated HT before age 48 (vs never users; OR 3.86, 95\% CI, 2.10-7.09), and the odds of depression increased with longer HT use $(P$-trend $<0.001) .{ }^{107}$ Not all studies of HT have shown adverse effects on mood, however. In the WHI trial, CE/MPA had a neutral effect on mood swings compared with placebo, ${ }^{24}$ and in the randomized, placebo-controlled KEEPS-Cognitive and Affective Study (KEEPS-Cog) of perimenopausal and early postmenopausal women, oral CE with cyclical oral micronized progesterone was found to significantly reduce tension-anxiety (small to medium effect size) and depression-dejection scores (medium effect size) on the Profile of Mood States compared with placebo. ${ }^{108}$ These benefits with regard to mood were not observed with transdermal estradiol plus oral micronized progesterone, though the formulations provided comparable benefits with regard to reduction of VMSs. ${ }^{108}$

Menopausal hormonal therapy may also adversely affect insulin sensitivity. In a randomized, placebo-controlled trial, 


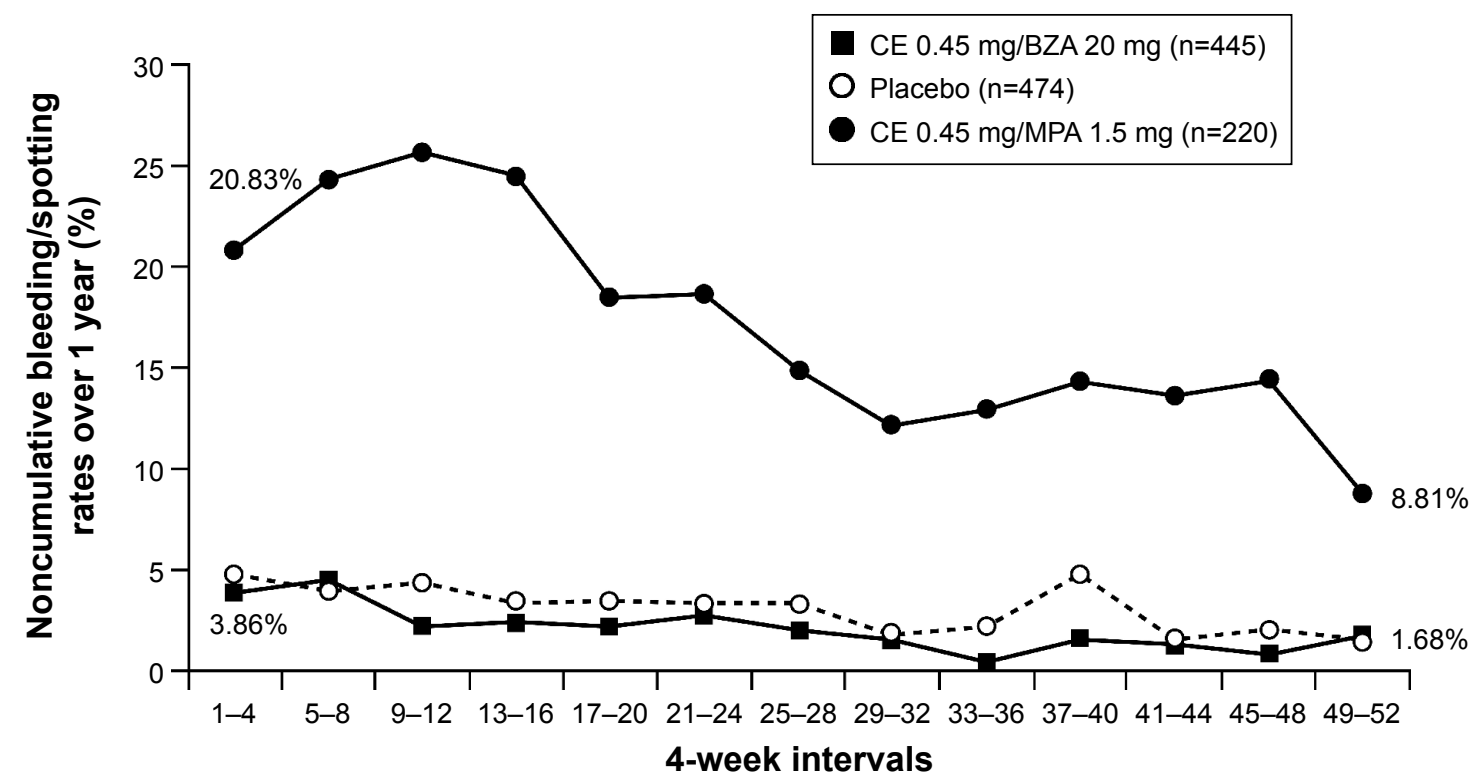

Figure 4 Bleeding/spotting rates over I year of treatment with CE/BZA compared to CE/MPA in SMART-5. ${ }^{104}$ Note: $P<0.001$ for all values versus $C E / M P A$.

Abbreviations: CE, conjugated estrogens; BZA, bazedoxifene; MPA, medroxyprogesterone acetate; SMART, Selective estrogens, Menopause, And Response to Therapy.

CE/MPA reduced insulin sensitivity by $17 \%$ without altering body composition, fat distribution, or body weight. ${ }^{109}$ The effect persisted throughout the 2 years of treatment but was reversible after treatment discontinuation. ${ }^{109}$ Other preclinical and clinical studies suggest that estrogens increase insulin sensitivity, but this effect is countered by progestogens, which are associated with hyperinsulinemia and decreased insulin sensitivity or glucose tolerance. ${ }^{110-112}$ Effects of CE/BZA on mood and insulin sensitivity have not been reported; however, women who experience these effects while taking estrogen/progestin therapy may wish to consider a trial of CE/BZA as an alternative, progestin-free option.

\section{Patient-specific outcomes}

Data from the SMART trials also indicate that CE/BZA improves various patient-reported outcomes, including menopause-specific quality of life, sleep, and treatment satisfaction.

Menopause-specific quality of life was evaluated in SMART-1, -2, -3, and -5 using the Menopause-Specific Quality of Life Questionnaire. ${ }^{113}$ Although the studies enrolled different populations (generally healthy women, women with moderate-to-severe VMSs, and women with vulvar-vaginal symptoms), both doses of CE/BZA significantly improved overall Menopause-Specific Quality of Life Questionnaire scores and vasomotor function subscale scores in all four studies at virtually all time points through 24 months. ${ }^{113}$ In the SMART trial participants with VMSs at baseline (SMART-2 and SMART-5), the improvements in vasomotor functioning with CE $0.45 \mathrm{mg} / \mathrm{BZA} 20 \mathrm{mg}$ versus placebo exceeded previously established, clinically important differences. ${ }^{113}$ Both doses of CE/BZA improved the sexual functioning domain score in SMART-1 and SMART-3, and the higher dose also improved sexual functioning scores in SMART-2 and SMART-5. ${ }^{113}$ Women in SMART-3, who had vulvar-vaginal symptoms at baseline, experienced the greatest improvements in sexual functioning, which were statistically significant, although they did not exceed clinically important differences. ${ }^{113}$

The effects of CE/BZA on sleep were evaluated in SMART-2 and SMART-5 using the Medical Outcomes Study (MOS) sleep scale. ${ }^{14,115}$ Both doses of CE/BZA significantly reduced the time it takes to fall asleep and the amount of sleep disturbance in both studies. ${ }^{114,115}$ Both doses also improved sleep adequacy as well as scores on two sleep indices from the MOS sleep scale measuring overall sleep problems in SMART-2, whereas improvements on these outcomes were seen only with CE $0.625 \mathrm{mg} / \mathrm{BZA} 20 \mathrm{mg}$ in SMART-5. ${ }^{114,115}$ Effect sizes for these improvements, reported in SMART-2, were medium to large. ${ }^{114}$ In SMART-5, CE/MPA also improved time to fall asleep, sleep disturbance, sleep adequacy, and both sleep problem indices on the MOS sleep scale compared with placebo. ${ }^{115}$

Using mediation modeling, Pinkerton et al ${ }^{116}$ concluded that at week 12 , a majority ( $78 \%-86 \%$ ) of CE/BZA's beneficial effects on sleep disturbance in the SMART-2 population 
of women with frequent moderate-to-severe hot flushes at baseline were attributable to direct effects rather than indirect effects resulting from reduction in the bothersomeness of hot flushes. However, the opposite was found in the SMART-5 population of women with less severe VMS: reduction of hot flushes accounted for $75 \%-92 \%$ of the effects on sleep disturbance. ${ }^{116}$ In an analysis of a subgroup of more symptomatic women in SMART-5, results were more comparable to those of SMART-2; thus, CE/BZA appears to affect sleep more directly in women who have severe VMSs but more indirectly via improvements in VMS in women with less severe VMSs. Similarly, benefits of CE/MPA on sleep disturbance in the overall SMART-5 population were largely (96\%-147\%) attributable to reduction in VMSs. ${ }^{116}$ This is consistent with results of another recent study, which found that transdermal estradiol did not improve sleep quality compared with placebo in postmenopausal women who had insomnia but not severe VMSs or hot flushes during sleep. ${ }^{117}$

Treatment satisfaction was assessed via the Menopause Symptoms-Treatment Satisfaction Questionnaire in SMART-2 and SMART-3. ${ }^{86,114}$ In both trials, CE $0.45 \mathrm{mg}$ / BZA $20 \mathrm{mg}$ and CE $0.625 \mathrm{mg} / \mathrm{BZA} 20 \mathrm{mg}$ were associated with significantly $(P<0.05)$ greater overall treatment satisfaction compared with placebo as well as greater satisfaction with control of daytime and nighttime hot flushes and effects on quality of sleep and mood/emotions. ${ }^{86,114}$ In the more symptomatic population in SMART-2, both doses of CE/ BZA were also associated with greater satisfaction with treatment tolerability, and the approved dose was also associated with greater satisfaction with ability to concentrate. ${ }^{114}$

\section{Conclusion}

CE/BZA is a good option for nonhysterectomized postmenopausal women who are seeking relief from bothersome menopausal symptoms; additionally, it avoids the use of a progestin. It is associated with significant benefits with regard to reduction of VMSs and prevention of bone loss, improves sleep and menopause-specific quality of life, and may improve vaginal lubrication and vaginal maturation index. Based on up to 2 years of follow-up, it provides acceptable protection of the endometrium and breast. Women using CE/ BZA report a high rate of treatment satisfaction.

The choice between traditional HT and CE/BZA should be based on safety and tolerability as well as personal preferences. HT regimens containing progestins have been associated with an increased risk of breast cancer, increased breast density, breast pain/tenderness, and vaginal bleeding. Progestin-containing HT may also have a negative effect on mood in some progestin-sensitive women. During up to 2 years of CE/BZA use, incidence of those outcomes is comparable to that with placebo and lower than that with CE/MPA.

The success and safety of the available formulation of CE/BZA are based on the careful selection of the estrogen component (in this case, conjugated estrogens) and SERM used in this combination product, as well as the identification of a dose ratio that provides the best balance between therapeutic efficacy and endometrial safety.

\section{Acknowledgments}

Medical writing support was provided by Lauren Cerruto at Peloton Advantage and was funded by Pfizer Inc. The Phase III SMART studies (NCT00808132, NCT00242710, NCT00234819, and NCT00675688) from which data on file have been reported here were sponsored by Wyeth Research, which was acquired by Pfizer Inc. in October 2009.

\section{Disclosure}

RK has served as a consultant/advisory board member for Amgen, Foundation for Osteoporosis Research and Education/ American Bone Health, Merck \& Co, Noven Pharmaceuticals, Novo Nordisk A/S, Own the Bone Advisory Board of the American Orthopedic Association, Pfizer, Shionogi, TherapeuticsMD, and Sprout; has received grants/research support (fees to Alta Bates Summit Medical Center, Jordan Research and Education Institute) from TherapeuticsMD; has served on a speaker's bureau for Novo Nordisk A/S, Shionogi, Noven Pharmaceuticals, and Pfizer; and has received editorial writing support from Pfizer and Shionogi. SRG has served as an advisory board member for Shionogi, Pfizer, JDS Therapeutics, Amgen, and Sermonix; served as a consultant for Cook OB/GYN and Philips Ultrasound; and has served on the speaker's bureaus for Pfizer, Shionogi, and JDS Therapeutics. JHP has received consultant fees from Wyeth/Pfizer, Besins Healthcare, Shionogi, Metagenics, Radius Health, and TherapeuticsMD, and has stock options in TherapeuticsMD. BSK is an employee of Pfizer. The authors report no other conflicts of interest in this work.

\section{References}

1. Politi MC, Schleinitz MD, Col NF. Revisiting the duration of vasomotor symptoms of menopause: a meta-analysis. J Gen Intern Med. 2008; 23(9):1507-1513.

2. Williams RE, Kalilani L, DiBenedetti DB, et al. Frequency and severity of vasomotor symptoms among peri- and postmenopausal women in the United States. Climacteric. 2008;11(1):32-43.

3. Nappi RE, Kokot-Kierepa M. Vaginal health: insights, views \& attitudes (VIVA) - results from an international survey. Climacteric. 2012;15(1): 36-44.

4. Freeman EW, Sammel MD, Sanders RJ. Risk of long-term hot flashes after natural menopause: evidence from the Penn Ovarian Aging Study cohort. Menopause. 2014;21(9):924-932. 
5. Gartoulla P, Worsley R, Bell RJ, Davis SR. Moderate to severe vasomotor and sexual symptoms remain problematic for women aged 60 to 65 years. Menopause. 2015;22(7):694-701.

6. Hemminki E, Regushevskaya E, Luoto R, Veerus P. Variability of bothersome menopausal symptoms over time - a longitudinal analysis using the Estonian postmenopausal hormone therapy trial (EPHT). BMC Womens Health. 2012;12:44.

7. GBD 2013 Mortality and Causes of Death Collaborators. Global, regional, and national age-sex specific all-cause and cause-specific mortality for 240 causes of death, 1990-2013: a systematic analysis for the Global Burden of Disease Study 2013. Lancet. 2015;385(9963):117-171.

8. Avis NE, Crawford SL, Greendale G, et al; Study of Women's Health Across the Nation. Duration of menopausal vasomotor symptoms over the menopause transition. JAMA Intern Med. 2015;175(4):531-539.

9. The North American Menopause Society. The 2012 hormone therapy position statement of The North American Menopause Society. Menopause. 2012;19(3):257-271.

10. Stuenkel CA, Gass ML, Manson JE, et al. A decade after the Women's Health Initiative - the experts do agree. Menopause. 2012;19(8): 846-847.

11. Shifren JL, Gass ML. The North American Menopause Society recommendations for clinical care of midlife women. Menopause. 2014; 21(10):1038-1062.

12. de Villiers TJ, Gass ML, Haines CJ, et al. Global consensus statement on menopausal hormone therapy. Climacteric. 2013;16(2):203-204.

13. de Villiers TJ, Pines A, Panay N, et al; International Menopause Society. Updated 2013 International Menopause Society recommendations on menopausal hormone therapy and preventive strategies for midlife health. Climacteric. 2013;16(3):316-337.

14. Neves-E-Castro M, Birkhauser M, Samsioe G, et al. EMAS position statement: the ten point guide to the integral management of menopausal health. Maturitas. 2015;81(1):88-92.

15. Kaunitz AM. Extended duration use of menopausal hormone therapy. Menopause. 2014;21(6):679-681

16. North American Menopause Society [webpage on the Internet]. The North American Menopause Society statement on continuing use of systemic hormone therapy after age 65. North American Menopause Society [updated 2015]. Available from: http:/www.menopause.org/ docs/default-source/2015/2015-nams-hormone-therapy-after-age-65. pdf. Accessed June 9, 2015.

17. Anderson GL, Limacher M, Assaf AR, et al; Women's Health Initiative Steering Committee. Effects of conjugated equine estrogen in postmenopausal women with hysterectomy: the Women's Health Initiative randomized controlled trial. JAMA. 2004;291(14):1701-1712.

18. Rossouw JE, Anderson GL, Prentice RL, et al; Writing Group for the Women's Health Initiative Investigators. Risks and benefits of estrogen plus progestin in healthy postmenopausal women: principal results from the Women's Health Initiative randomized controlled trial. JAMA 2002;288(3):321-333.

19. Manson JE, Chlebowski RT, Stefanick ML, et al. Menopausal hormone therapy and health outcomes during the intervention and extended poststopping phases of the Women's Health Initiative randomized trials. JAMA. 2013;310(13):1353-1368.

20. Hays J, Ockene JK, Brunner RL, et al; Women's Health Initiative Investigators. Effects of estrogen plus progestin on health-related quality of life. N Engl J Med. 2003;348(19):1839-1854.

21. Chlebowski RT, Hendrix SL, Langer RD, et al; WHI Investigators. Influence of estrogen plus progestin on breast cancer and mammography in healthy postmenopausal women: the Women's Health Initiative randomized trial. JAMA. 2003;289(24):3243-3253.

22. Chlebowski RT, Anderson GL, Gass M, et al; WHI Investigators. Estrogen plus progestin and breast cancer incidence and mortality in postmenopausal women. JAMA. 2010;304(15):1684-1692.

23. Anderson GL, Chlebowski RT, Aragaki AK, et al. Conjugated equine oestrogen and breast cancer incidence and mortality in postmenopausal women with hysterectomy: extended follow-up of the Women's Health Initiative randomised placebo-controlled trial. Lancet Oncol. 2012;13(5):476-486
24. Barnabei VM, Cochrane BB, Aragaki AK, et al; Women's Health Initiative Investigators. Menopausal symptoms and treatment-related effects of estrogen and progestin in the Women's Health Initiative. Obstet Gynecol. 2005;105(5 pt 1):1063-1073.

25. Regan MM, Emond SK, Attardo MJ, Parker RA, Greenspan SL. Why do older women discontinue hormone replacement therapy? J Womens Health Gend Based Med. 2001;10(4):343-350.

26. Ameye L, Antoine C, Paesmans M, de Azambuja E, Rozenberg S. Menopausal hormone therapy use in 17 European countries during the last decade. Maturitas. 2014;79(3):287-291.

27. Sprague BL, Trentham-Dietz A, Cronin KA. A sustained decline in postmenopausal hormone use: results from the National Health and Nutrition Examination Survey, 1999-2010. Obstet Gynecol. 2012;120(3):595-603.

28. Lohr A. [webpage on the Internet]. First of its kind "menopause map" helps women navigate treatment [updated 2015]. Available from: https://www.endocrine.org/news-room/press-release-archives/2012/ first-of-its-kind-menopause-map-helps-women-navigate-treatment. Accessed July 2, 2015.

29. Sarrel P, Portman D, Lefebvre P, et al. Incremental direct and indirect costs of untreated vasomotor symptoms. Menopause. 2015;22(3): 260-266.

30. Utian WH. Psychosocial and socioeconomic burden of vasomotor symptoms in menopause: a comprehensive review. Health Qual Life Outcomes. 2005;3:47.

31. Gartoulla P, Bell RJ, Worsley R, Davis SR. Moderate-severely bothersome vasomotor symptoms are associated with lowered psychological general wellbeing in women at midlife. Maturitas. 2015;81(4):487-492.

32. Simon JA, Nappi RE, Kingsberg SA, Maamari R, Brown V. Clarifying vaginal atrophy's impact on sex and relationships (CLOSER) survey: emotional and physical impact of vaginal discomfort on North American postmenopausal women and their partners. Menopause. 2014;21(2):137-142.

33. Simon JA, Kokot-Kierepa M, Goldstein J, Nappi RE. Vaginal health in the United States: results from the vaginal health: insights, views \& attitudes survey. Menopause. 2013;20(10):1043-1048.

34. Pinkerton JV, Santoro N. Compounded bioidentical hormone therapy: identifying use trends and knowledge gaps among US women. Menopause. 2015;22(9):926-936.

35. American College of Obstetricians and Gynecologists. [webpage on the Internet]. Committee opinion no. 532: compounded bioidentical menopausal hormone therapy. [updated August, 2012]. Available from: http://www.acog.org/Resources-And-Publications/Committee-Opinions/ Committee-on-Gynecologic-Practice/Compounded-BioidenticalMenopausal-Hormone-Therapy. Accessed August 21, 2014.

36. Rossouw JE, Prentice RL, Manson JE, et al. Postmenopausal hormone therapy and risk of cardiovascular disease by age and years since menopause. JAMA. 2007;297(13):1465-1477.

37. The North American Menopause Society. Management of symptomatic vulvovaginal atrophy: 2013 position statement of The North American Menopause Society. Menopause. 2013;20(9):888-902.

38. Goodman MP. Are all estrogens created equal? A review of oral vs. transdermal therapy. J Womens Health (Larchmt). 2012;21(2):161-169.

39. Files JA, Miller VM, Cha SS, Pruthi S. Effects of different hormone therapies on breast pain in recently postmenopausal women: findings from the Mayo Clinic KEEPS breast pain ancillary study. $J$ Womens Health (Larchmt). 2014;23(10):801-805.

40. Kling JM, Lahr BA, Bailey KR, Harman SM, Miller VM, Mulvagh SL. Endothelial function in women of the Kronos Early Estrogen Prevention Study. Climacteric. 2015;18(2):187-197.

41. Miller VM, Lahr BD, Bailey KR, Heit JA, Harman SM, Jayachandran M. Longitudinal effects of menopausal hormone treatments on platelet characteristics and cell-derived microvesicles. Platelets. 2015. Epub 2015 Apr 9.

42. Osphena [package insert]. Florham Park, NJ: Shionogi Inc.; 2015.

43. Bachmann GA, Komi JO. Ospemifene effectively treats vulvovaginal atrophy in postmenopausal women: results from a pivotal phase 3 study. Menopause. 2010;17(3):480-486. 
44. Portman DJ, Bachmann GA, Simon JA. Ospemifene, a novel selective estrogen receptor modulator for treating dyspareunia associated with postmenopausal vulvar and vaginal atrophy. Menopause. 2013;20(6):623-630.

45. Portman DJ, Gass ML. Genitourinary syndrome of menopause: new terminology for vulvovaginal atrophy from the International Society for the Study of Women's Sexual Health and the North American Menopause Society. Menopause. 2014;21(10):1063-1068.

46. Simon JA, Lin VH, Radovich C, Bachmann GA. One-year long-term safety extension study of ospemifene for the treatment of vulvar and vaginal atrophy in postmenopausal women with a uterus. Menopause. 2013;20(4):418-427.

47. McClung MR, Siris E, Cummings S, et al. Prevention of bone loss in postmenopausal women treated with lasofoxifene compared with raloxifene. Menopause. 2006;13(3):377-386.

48. Fisher B, Costantino JP, Wickerham DL, et al. Tamoxifen for prevention of breast cancer: report of the National Surgical Adjuvant Breast and Bowel Project P-1 Study. J Natl Cancer Inst. 1998;90(18): 1371-1388.

49. Christiansen C, Chesnut CH 3rd, Adachi JD, et al. Safety of bazedoxifene in a randomized, double-blind, placebo- and active-controlled Phase 3 study of postmenopausal women with osteoporosis. BMC Musculoskelet Disord. 2010;11:130.

50. Brisdelle [package insert]. Miami, FL: Noven Therapeutics, LLC; 2013.

51. Simon JA, Portman DJ, Kaunitz AM, et al. Low-dose paroxetine $7.5 \mathrm{mg}$ for menopausal vasomotor symptoms: two randomized controlled trials. Menopause. 2013;20(10):1027-1035.

52. Portman DJ, Kaunitz AM, Kazempour K, Mekonnen H, Bhaskar S, Lippman J. Effects of low-dose paroxetine $7.5 \mathrm{mg}$ on weight and sexual function during treatment of vasomotor symptoms associated with menopause. Menopause. 2014;21(10):1082-1090.

53. Pinkerton JV, Archer DF, Guico-Pabia CJ, Hwang E, Cheng RF. Maintenance of the efficacy of desvenlafaxine in menopausal vasomotor symptoms: a 1-year randomized controlled trial. Menopause. 2013; 20(1):38-46.

54. ClinicalTrials.gov [webpage on the Internet]. Estradiol vaginal softgel capsules in treating symptoms of vulvar and vaginal atrophy in postmenopausal women (REJOICE) NCT02253173. ClinicalTrials.gov [updated April 28, 2015]. Available from: https://www.clinicaltrials. gov/ct2/show/NCT02253173. Accessed June 9, 2015.

55. Mirkin S, Amadio JM, Bernick BA, Pickar JH, Archer DF. 17betaEstradiol and natural progesterone for menopausal hormone therapy: REPLENISH phase 3 study design of a combination capsule and evidence review. Maturitas. 2015;81(1):28-35.

56. Pickar JH, Bon C, Amadio JM, Mirkin S, Bernick B. Pharmacokinetics of the first combination 17beta-estradiol/progesterone capsule in clinical development for menopausal hormone therapy. Menopause. 2015;22(12):1308-1316.

57. ClinicalTrials.gov [webpage on the Internet]. A safety and efficacy study of the combination estradiol and progesterone to treat vasomotor symptoms (REPLENISH) NCT01942668. ClinicalTrials.gov [updated May 5, 2015]. Available from: http://www.clinicaltrials.gov/ct2/show/ NCT01942668?term=REPLENISH\&rank=1. Accessed June 9, 2015.

58. Freeman EW, Guthrie KA, Caan B, et al. Efficacy of escitalopram for hot flashes in healthy menopausal women: a randomized controlled trial. JAMA. 2011;305(3):267-274.

59. Gordon PR, Kerwin JP, Boesen KG, Senf J. Sertraline to treat hot flashes: a randomized controlled, double-blind, crossover trial in a general population. Menopause. 2006;13(4):568-575.

60. Joffe H, Guthrie KA, LaCroix AZ, et al. Low-dose estradiol and the serotonin-norepinephrine reuptake inhibitor venlafaxine for vasomotor symptoms: a randomized clinical trial. JAMA Intern Med. 2014;174(7):1058-1066.

61. Pinkerton JV, Kagan R, Portman D, Sathyanarayana R, Sweeney M. Phase 3 randomized controlled study of gastroretentive gabapentin for the treatment of moderate-to-severe hot flashes in menopause. Menopause. 2014;21(6):567-573.
62. Kharode Y, Bodine PV, Miller CP, Lyttle CR, Komm BS. The pairing of a selective estrogen receptor modulator, bazedoxifene, with conjugated estrogens as a new paradigm for the treatment of menopausal symptoms and osteoporosis prevention. Endocrinology. 2008;149(12):6084-6091.

63. Komm BS, Mirkin S, Jenkins SN. Development of conjugated estrogens/ bazedoxifene, the first tissue selective estrogen complex (TSEC) for management of menopausal hot flashes and postmenopausal bone loss. Steroids. 2014;90:71-81.

64. Sweetland S, Beral V, Balkwill A, et al; Million Women Study Collaborators. Venous thromboembolism risk in relation to use of different types of postmenopausal hormone therapy in a large prospective study. J Thromb Haemost. 2012;10:2277-2286.

65. Smith NL, Blondon M, Wiggins KL, et al. Lower risk of cardiovascular events in postmenopausal women taking oral estradiol compared with oral conjugated equine estrogens. JAMA Intern Med. 2014;174(1):25-31.

66. Shufelt CL, Merz CN, Prentice RL, et al. Hormone therapy dose, formulation, route of delivery, and risk of cardiovascular events in women: findings from the Women's Health Initiative Observational Study. Menopause. 2014;21(3):260-266.

67. Ethun KF, Wood CE, Cline JM, Register TC, Appt SE, Clarkson TB. Endometrial profile of bazedoxifene acetate alone and in combination with conjugated equine estrogens in a primate model. Menopause. 2013;20(7):777-784.

68. Ethun KF, Wood CE, Register TC, Cline JM, Appt SE, Clarkson TB. Effects of bazedoxifene acetate with and without conjugated equine estrogens on the breast of postmenopausal monkeys. Menopause. 2012;19(11):1242-1252.

69. Kulak J Jr, Fischer C, Komm B, Taylor HS. Treatment with bazedoxifene, a selective estrogen receptor modulator, causes regression of endometriosis in a mouse model. Endocrinology. 2011;152(8): 3226-3232.

70. Lewis-Wambi JS, Kim H, Curpan R, Grigg R, Sarker MA, Jordan VC. The selective estrogen receptor modulator bazedoxifene inhibits hormone-independent breast cancer cell growth and downregulates estrogen receptor alpha and cyclin D1. Mol Pharmacol. 2011;80(4):610-620

71. Wardell SE, Nelson ER, Chao CA, McDonnell DP. Bazedoxifene exhibits antiestrogenic activity in animal models of tamoxifen-resistant breast cancer: implications for treatment of advanced disease. Clin Cancer Res. 2013;19(9):2420-2431.

72. Peano BJ, Crabtree JS, Komm BS, Winneker RC, Harris HA. Effects of various selective estrogen receptor modulators with or without conjugated estrogens on mouse mammary gland. Endocrinology. 2009;150(4):1897-1903.

73. Chang KC, Wang Y, Bodine PV, Nagpal S, Komm BS. Gene expression profiling studies of three SERMs and their conjugated estrogen combinations in human breast cancer cells: insights into the unique antagonistic effects of bazedoxifene on conjugated estrogens. J Steroid Biochem Mol Biol. 2010;118(1-2):117-124.

74. Song Y, Santen RJ, Wang JP, Yue W. Inhibitory effects of a bazedoxifene/conjugated equine estrogen combination on human breast cancer cells in vitro. Endocrinology. 2013;154(2):656-665.

75. Stovall DW, Utian WH, Gass ML, et al. The effects of combined raloxifene and oral estrogen on vasomotor symptoms and endometrial safety. Menopause. 2007;14(3 pt 1):510-517.

76. Van Duren D, Ronkin S, Pickar J, Constantine G. Bazedoxifene combined with conjugated estrogens: a novel alternative to traditional hormone therapies [abstract O-206]. Fertil Steril. 2006;86(3 suppl):S88-S89.

77. Pickar JH, Yeh IT, Bachmann G, Speroff L. Endometrial effects of a tissue selective estrogen complex containing bazedoxifene/ conjugated estrogens as a menopausal therapy. Fertil Steril. 2009;92(3): 1018-1024.

78. Lobo RA, Pinkerton JV, Gass ML, et al. Evaluation of bazedoxifene/ conjugated estrogens for the treatment of menopausal symptoms and effects on metabolic parameters and overall safety profile. Fertil Steril. 2009;92(3):1025-1038. 
79. Pinkerton JV, Utian WH, Constantine GD, Olivier S, Pickar JH. Relief of vasomotor symptoms with the tissue-selective estrogen complex containing bazedoxifene/conjugated estrogens: a randomized, controlled trial. Menopause. 2009;16(6):1116-1124.

80. Freeman EW, Ensrud KE, Larson JC, et al. Placebo improvement in pharmacologic treatment of menopausal hot flashes: time course, duration, and predictors. Psychosom Med. 2015;77(2):167-175.

81. Pinkerton JV, Abraham L, Bushmakin AG, et al. Evaluation of the efficacy and safety of bazedoxifene/conjugated estrogens for secondary outcomes including vasomotor symptoms in postmenopausal women by years since menopause in the Selective estrogens, Menopause, And Response to Therapy (SMART) trials. $J$ Womens Health (Larchmt). 2014;23(1):18-28.

82. Lindsay R, Gallagher JC, Kagan R, Pickar JH, Constantine G. Efficacy of tissue-selective estrogen complex of bazedoxifene/conjugated estrogens for osteoporosis prevention in at-risk postmenopausal women. Fertil Steril. 2009;92(3):1045-1052.

83. Mirkin S, Komm BS, Pan K, Chines AA. Effects of bazedoxifene/ conjugated estrogens on endometrial safety and bone in postmenopausal women. Climacteric. 2013;16(3):338-346.

84. Pinkerton JV, Harvey JA, Lindsay R, et al; SMART-5 Investigators. Effects of bazedoxifene/conjugated estrogens on the endometrium and bone: a randomized trial. J Clin Endocrinol Metab. 2014;99(2): E189-E198.

85. Kagan R, Williams RS, Pan K, Mirkin S, Pickar JH. A randomized, placebo- and active-controlled trial of bazedoxifene/conjugated estrogens for treatment of moderate to severe vulvar/vaginal atrophy in postmenopausal women. Menopause. 2010;17(2):281-289.

86. Bachmann G, Bobula J, Mirkin S. Effects of bazedoxifene/conjugated estrogens on quality of life in postmenopausal women with symptoms of vulvar/vaginal atrophy. Climacteric. 2010;13(2):132-140.

87. Guidance for Industry [webpage on the Internet]. Estrogen and estrogen/ progestin drug products to treat vasomotor symptoms and vulvar and vaginal atrophy symptoms - recommendaitons for clinical evaluation. Food and Drug Administration [updated January, 2003]. Available from: http://www.fda.gov/downloads/drugs/guidancecomplianceregulatoryinformation/guidances/ucm071643.pdf. Accessed January 6, 2014.

88. European Medicines Agency [webpage on the Internet]. Guideline on clinical investigation of medicinal products for hormone replacement therapy of oestrogen deficiency symptoms in postmenopausal women. European Medicines Agency [updated May 1, 2006]. Available from: http://www.ema. europa.eu/docs/en_GB/document_library/Scientific_guideline/2009/09/ WC500003348.pdf. Accessed May 19, 2014.

89. Kulak J Jr, Ferriani RA, Komm BS, Taylor HS. Tissue selective estrogen complexes (TSECs) differentially modulate markers of proliferation and differentiation in endometrial cells. Reprod Sci. 2013;20(2):129-137.

90. Clarke CL, Sutherland RL. Progestin regulation of cellular proliferation. Endocr Rev. 1990;11(2):266-301.

91. Mirkin S, Pinkerton JV, Kagan R, et al. Gynecologic safety of conjugated estrogens plus bazedoxifene: pooled analysis of 5 phase 3 trials. $J$ Womens Health. Accepted for publication.

92. Palacios S, Silverman SL, de Villiers TJ, et al; Bazedoxifene Study Group. A 7-year randomized, placebo-controlled trial assessing the long-term efficacy and safety of bazedoxifene in postmenopausal women with osteoporosis: effects on bone density and fracture. Menopause. 2015;22(8):806-813.

93. Harvey JA, Pinkerton JV, Baracat EC, Shi H, Chines AA, Mirkin S. Breast density changes in a randomized controlled trial evaluating bazedoxifene/ conjugated estrogens. Menopause. 2013;20(2):138-145.

94. Pinkerton JV, Harvey JA, Pan K, et al. Breast effects of bazedoxifeneconjugated estrogens: a randomized controlled trial. Obstet Gynecol. 2013;121(5):959-968.

95. Crandall CJ, Aragaki AK, Cauley JA, et al. Breast tenderness after initiation of conjugated equine estrogens and mammographic density change. Breast Cancer Res Treat. 2012;131(3):969-979.
96. Assi V, Massat NJ, Thomas S, et al. A case-control study to assess the impact of mammographic density on breast cancer risk in women aged 40-49 at intermediate familial risk. Int J Cancer. 2015;136(10): 2378-2387.

97. Boyd NF, Lockwood GA, Byng JW, Tritchler DL, Yaffe MJ. Mammographic densities and breast cancer risk. Cancer Epidemiol Biomarkers Prev. 1998;7(12):1133-1144.

98. Carney PA, Miglioretti DL, Yankaskas BC, et al. Individual and combined effects of age, breast density, and hormone replacement therapy use on the accuracy of screening mammography. Ann Intern Med. 2003;138(3):168-175.

99. Palacios S, de Villiers TJ, Nardone FC, et al; BZA Study Group. Assessment of the safety of long-term bazedoxifene treatment on the reproductive tract in postmenopausal women with osteoporosis: results of a 7-year, randomized, placebo-controlled, phase 3 study. Maturitas. 2013;76(1):81-87.

100. Komm BS, Thompson JR, Mirkin S. Cardiovascular safety of conjugated estrogens plus bazedoxifene: meta-analysis of the SMART trials. Climacteric. 2015;18:1-19.

101. Curb JD, Prentice RL, Bray PF, et al. Venous thrombosis and conjugated equine estrogen in women without a uterus. Arch Intern Med. 2006;166(7):772-780.

102. Mirkin S, Pan K, Ryan KA, Chines A, Stevenson JC. A pooled analysis of the effects of conjugated estrogens/bazedoxifene on lipid parameters in postmenopausal women from the Selective estrogens, Menopause, And Response to Therapy (SMART) trials. J Clin Endocrinol Metab. 2015;100(6):2329-2338.

103. Archer DF, Lewis V, Carr BR, Olivier S, Pickar JH. Bazedoxifene/ conjugated estrogens $(\mathrm{BZA} / \mathrm{CE})$ : incidence of uterine bleeding in postmenopausal women. Fertil Steril. 2009;92(3):1039-1044.

104. Goldstein SR, Kagan R. Incidence of bleeding or spotting with a conjugated estrogen/bazedoxifene compound compared to conjugated estrogen/progestogen to placebo. Poster P-31 Presented at: Annual Meeting of the North American Menopause Society; September 30-October 3, 2015; Las Vegas, NV.

105. Crandall CJ, Aragaki AK, Cauley JA, et al. Breast tenderness and breast cancer risk in the estrogen plus progestin and estrogen-alone Women's Health Initiative clinical trials. Breast Cancer Res Treat. 2012;132(1):275-285.

106. Girdler SS, O’Briant C, Steege J, Grewen K, Light KC. A comparison of the effect of estrogen with or without progesterone on mood and physical symptoms in postmenopausal women. $J$ Womens Health Gend Based Med. 1999;8(5):637-646.

107. Jung SJ, Shin A, Kang D. Hormone-related factors and post-menopausal onset depression: results from KNHANES (2010-2012). J Affect Disord. 2015;175:176-183.

108. Gleason CE, Dowling NM, Wharton W, et al. Effects of hormone therapy on cognition and mood in recently postmenopausal women: findings from the randomized, controlled KEEPS-cognitive and affective study. PLoS Med. 2015;12(6):e1001833.

109. Sites CK, L'Hommedieu GD, Toth MJ, Brochu M, Cooper BC, Fairhurst PA. The effect of hormone replacement therapy on body composition, body fat distribution, and insulin sensitivity in menopausal women: a randomized, double-blind, placebo-controlled trial. J Clin Endocrinol Metab. 2005;90(5):2701-2707.

110. Godsland IF, Gangar K, Walton C, et al. Insulin resistance, secretion, and elimination in postmenopausal women receiving oral or transdermal hormone replacement therapy. Metabolism. 1993; 42(7):846-853.

111. Shadoan MK, Kavanagh K, Zhang L, Anthony MS, Wagner JD. Addition of medroxyprogesterone acetate to conjugated equine estrogens results in insulin resistance in adipose tissue. Metabolism. 2007;56(6):830-837.

112. Spencer CP, Godsland IF, Cooper AJ, Ross D, Whitehead MI, Stevenson JC. Effects of oral and transdermal 17beta-estradiol with cyclical oral norethindrone acetate on insulin sensitivity, secretion, and elimination in postmenopausal women. Metabolism. 2000;49(6):742-747. 
113. Abraham L, Pinkerton JV, Messig M, Ryan KA, Komm BS, Mirkin S. Menopause-specific quality of life across varying menopausal populations with conjugated estrogens/bazedoxifene. Maturitas. 2014;78(3):212-218.

114. Utian W, Yu H, Bobula J, Mirkin S, Olivier S, Pickar JH. Bazedoxifene/ conjugated estrogens and quality of life in postmenopausal women. Maturitas. 2009;63(4):329-335.

115. Pinkerton JV, Pan K, Abraham L, et al. Sleep parameters and healthrelated quality of life with bazedoxifene/conjugated estrogens: a randomized trial. Menopause. 2014;21(3):252-259.
116. Pinkerton JV, Bushmakin AG, Racketa J, Cappelleri JC, Chines AA, Mirkin S. Evaluation of the direct and indirect effects of bazedoxifene/ conjugated estrogens on sleep disturbance using mediation modeling. Menopause. 2014;21(3):243-251.

117. Tansupswatdikul P, Chaikittisilpa S, Jaimchariyatam N, Panyakhamlerd K, Jaisamrarn U, Taechakraichana N. Effects of estrogen therapy on postmenopausal sleep quality regardless of vasomotor symptoms: a randomized trial. Climacteric. 2015;18(2):198-204.

\section{Publish your work in this journal}

Therapeutics and Clinical Risk Management is an international, peerreviewed journal of clinical therapeutics and risk management, focusing on concise rapid reporting of clinical studies in all therapeutic areas, outcomes, safety, and programs for the effective, safe, and sustained use of medicines. This journal is indexed on PubMed Central, CAS,
EMBase, Scopus and the Elsevier Bibliographic databases. The manuscript management system is completely online and includes a very quick and fair peer-review system, which is all easy to use. Visit http://www.dovepress.com/testimonials.php to read real quotes from published authors.

Submit your manuscript here: http://www.dovepress.com/therapeutics-and-clinical-risk-management-journal 